\title{
Unleashing talent in mental health sciences: gender equality at the top
}

Josefien J. F. Breedvelt, Sarah Rowe, Henrietta Bowden-Jones,

Sunita Shridhar, Kate Lovett, Claudi Bockting, Anne Lingford-Hughes,

Geraldine Strathdee and Derek K. Tracy

\section{Summary}

Society is undergoing a shift in gender politics. Science and medicine are part of this conversation, not least as women's representation and pay continue to drop as one progresses through more senior academic and clinical levels. Naming and redressing these inequalities needs to be a priority for us all.

\section{Declaration of interest}

None.

\section{Keywords}

Gender; equality; psychiatry; workforce.

\section{Copyright and usage}

(C) The Royal College of Psychiatrists 2018
Josefien J. F. Breedvelt (pictured) is research lead at the Mental Health Foundation, London and a PhD candidate in the Department of Psychiatry at the Amsterdam UMC University of Amsterdam, the Netherlands; Sarah Rowe is a lecturer in the Division of Psychiatry, University College London, UK; Henrietta Bowden-Jones is a consultant psychiatrist at CNWL Foundation Trust, London and honorary clinical senior lecturer at Imperial College London and President of the Medical Women's Federation, UK; Sunita Shridhar is a general practitioner at Maylands Practice, Essex, UK; Kate Lovett is a consultant psychiatrist at Devon Partnership Trust and Dean of the Royal College of Psychiatrists, London, UK; Claudi Bockting is professor of clinical psychology in the Department of Psychiatry at Amsterdam UMC, University of Amsterdam, the Netherlands; Anne Lingford-Hughes is a consultant psychiatrist, professor of addiction biology and head of the Centre for Psychiatry at Imperial College London and the Chair of the Royal College of Psychiatry's Academic Faculty, UK; Geraldine Strathdee is a

consultant psychiatrist and was the National Clinical Director for Mental Health from 2013 to 2016; Derek K. Tracy is a consultant psychiatrist and clinical director at Oxleas NHS Foundation Trust London and a senior lecturer at King's College London, UK.

\section{8: a suffrage centenary, \#MeToo and gender pay gaps}

2018 is the centenary of women's suffrage in the UK. This sits in the contemporary landscape of the \#MeToo movement, debate on the persisting gender pay gap and representation of women at board level. Where are we in science, medicine and psychiatry? A recent podcast recorded at the Royal College of Psychiatrists hosted academics, clinicians and policy advisors discussing work by Carter et $a l^{1}$ on women in academic environments. That paper noted how women were less likely than men to ask questions at seminars and conferences. It opened podcast conversations on participants' reflections and perceptions of this, and the related ethos and culture of their employers.

This matters enormously. Women were described as 'literally less visible' by Carter and colleagues, and it appears to map onto career progression. Women are continuing to outnumber men at tertiary education, but only in more junior positions. In Europe, across all academic subjects they account for: $59 \%$ of undergraduates, $47 \%$ of $\mathrm{PhD}$ graduates, $45 \%$ of fixed-term contract postdoctoral researchers, and $37 \%$ of junior and $21 \%$ of senior faculty positions. In the UK, women account for a fifth of overall professorship and head of institution positions. The issue is particularly problematic in STEM subjects (science, technology, engineering, and mathematics), where women have historically been underrepresented; Hewlitt et $a l^{2}$ found that leave rates for women in these subjects peak about 10 years into their careers. Within academic medicine, the picture has been improving over the past decade, though there is variation by specialty. Primary care has the highest rate of women clinical academics (about 46\%); at about $30 \%$, psychiatry is not the worst (surgery is), but just about sits in the top half, above radiology and below paediatrics. ${ }^{3}$

\section{Senior academic, clinical and managerial under-representation: an end-game of less pay}

The academic output of women has been shown to be less often cited, and they suffer from underrepresentation in authorship. A recent paper in Nature found an inverse relationship between journal impact factor and women who were either first or last author. ${ }^{4}$ It is not clear which factors are at play; there are the aforementioned issues of fewer women in senior academic positions, but also concern about reviewer bias. There is mixed evidence about the effects of double blind reviewing, and concern that even with such measures authors can often be identified.

In clinical life in the UK we see a similar picture. Over half of foundation doctors are women, dropping to $36 \%$ at consultant level; at $43 \%$ this is somewhat better specifically in psychiatry, and this represents an increase of $3 \%$ over the last 5 years. However, this figure hides considerable variation between clinical subspecialties: women make up about $37 \%$ of consultants in Forensic psychiatry, whereas within child and adolescent mental health this climbs to approximately $64 \%$. It is important to note that nontraining, non-consultant grades make up $24 \%$ of medical workforce within psychiatry, where women continue to be over-represented at $54 \%{ }^{5}$ This report does not include linked data on ethnicity. Given the known impact of intersectionality on women's opportunities this missing data is clearly crucial for further research in identifying areas for targeting policy. We know that psychiatry relies heavily on international medical graduates, $65 \%$ of whom are Black and Minority Ethnic (BME). General Medical Council data show 37\% of the overall psychiatry medical workforce are from BME backgrounds. Full equality by numbers (forgetting whole time equivalents) is estimated to take another two decades. In primary care, women account for more than $50 \%$ of the workforce, but only $16 \%$ of CCG Chairs. The 'leaky pipeline' persists, with reducing women representation with seniority in terms of career progression, resulting in a loss of talent and diversity, a loss to the individuals concerned and a loss to academic and clinical institutions. 
In management and leadership roles, implicit and explicit bias may be an issue with different attributes and skills frequently ascribed to men and women. In evaluations and reference letters, the language used is often less favourable to women's natural abilities, ${ }^{6}$ who are frequently lauded for their 'hard work' rather than their 'brilliance'. It has been argued that women more commonly take on 'less rewarded' roles such as sitting on committees, having organizational responsibilities, mentoring others and teaching. These duties receive less acknowledgement and take time away from other important areas, hindering promotion. ${ }^{7}$ The truth remains that even in 2018, women are far more likely to take on a 'double shift' - having the bulk of domestic responsibilities as well as a professional life.

Differences are also reflected in pay. Across the whole NHS there is an overall pay gap of $8.6 \%$ in favour of men; amongst doctors this is even wider, women earning an average 34\% less, which has expanded over the last decade. This year, the BBC reported on how 95 of the 100 highest earning doctors in the UK are men, with full-time consultants earning on average $£ 14000$ more than women in equivalent positions. Some of the contributing factors to these figures are well recognized, including higher rates of flexible training, part-time working and subsequently additional time required to attain higher positions. However, fewer women are applying for, and receiving, clinical excellence awards (CEAs). Data for this vary locally, but it has been proposed as one of the drivers to change the existing award scheme. Interestingly, this does not appear to be as pronounced for local CEAs in academia, with approximately equal percentages of men and women holding them. However far fewer women in academia held national CEAs - just under a quarter, compared with over $40 \%$ of men - though, importantly, they were equally likely to be successful at attaining one when they applied. ${ }^{3}$ Women appear not to be putting themselves forward for these awards: at the very top of the scale, six and a half times more men than women have a platinum award.

\section{Next steps: the right thing is the best thing - unleashing talent}

What should we be doing about this as a profession? Awareness of the issues, measuring, benchmarking and challenging them, and looking for mechanisms for local redress are a start. The Athena SWAN charter is noteworthy in higher education for supporting institutes in improving measures of equality, such as progression of students into academia, career journeys of staff and the work environment. Within the Royal College of Psychiatrists, respect is a defined key organizational value which includes challenging inequality. To ensure that a commitment to narrowing the gaps in gender equality runs through all college policy, the College has recently appointed its first Associate Dean for Equality, Diversity and Inclusion.

There are recognized criteria for good leadership, including targeting leadership biases which can allow departmental or organizational evaluation to ensure an environment that encourages women's leadership to flourish. An example is the Aurora Leadership Scheme that promotes exposure, mentoring and meaningful management opportunities. Those in senior positions - men as well as women - have particular responsibilities and means to support the next generation of diverse talent to reach the top. We have seldom had so many medical Royal Colleges - including our own - led by women, and both our current National Mental Health Director and previous National Clinical Director for Mental Health have high visibility. The President of the Royal College of Physicians, Professor Jane Dacre, is leading an independent review into the gender pay gap for doctors that will keep this conversation alive.
However, there are limits to what any organisation can achieve, until more fundamental societal causes of inequality are addressed. Men are a crucial part of this conversation; for too long many men saw inequity as a 'women's issue' - it is a societal issue including welfare policy and cultural attitudes and practices in terms of child care and part-time working. ${ }^{8}$ Other intersectional issues can scarcely be done justice in a single editorial, but we are reminded that only $2 \%$ of professors in the UK are female and from BME backgrounds. Goldin ${ }^{9}$ argued that the largest advance to career attainment gap in the labour market is to improve temporal flexibility. Changes in how jobs are structured, with more flexibility in work hours, and less reward for working long hours might help. Indeed, this is one of the key pillars of Nordic policies for gender equality which, alongside investment in gender equal workplaces and free childcare, have contributed to creating some of the most gender-equal labour markets.

Equality is not just about having a level playing field, it is about unleashing talent. As well as being the 'right thing to do', the aforementioned Nordic model has been shown to have contributed considerably to economic growth, re-emphasizing the societal loss from inequity. Work by the Center for Creative Leadership (CCL), the primary community of leading and emerging women entrepreneurs and executives in Silicon Valley, ${ }^{10}$ has shown that greater senior female leadership improves perceived line management support, employee engagement and organisational dedication, whilst reducing staff burnout.

We finish by throwing a couple of challenges to the BJPsych and the academic publishing sector. Firstly, we would welcome a review of the processes and commitments toward female representation on publication and in leadership positions. Secondly, a quick look at the stats show that most journals still have unequal representation of women at editorial board level. Looking at the New England Journal of Medicine, Nature, Annual Review of Psychology, JAMA psychiatry and the BMJ, between 22 and 50 percent of editorial boards are female. To adopt another of 2018's hashtags, as \#immodestwomen we say that's better than it was a decade ago, but not good enough. We hope that the BJPsych, with about a third of women on the board, will lead the way in creating equality.

Josefien J. F. Breedvelt, MSC (D), Research Lead, The Mental Health Foundation, London, UK and PhD Candidate, Amsterdam UMC, Department of Psychiatry, University of Amsterdam, Department of Psychiatry, the Netherlands; Sarah Rowe, PhD, Lecturer, Division of Psychiatry, University College London, UK; Henrietta Bowden-Jones, FRCPsych, Consultant Psychiatrist, CNWL Foundation Trust, London and Honorary Clinical Senior Lecturer, Imperial College London and President, Medical Women's Federation, UK; Sunita Shridhar, MBBS, General Practitioner, Maylands Practice, Essex, UK; Kate Lovett, FRCPsych, Consultant Psychiatrist, Devon Partnership Trust and Dean, Royal College of Psychiatrists, UK; Claudi Bockting, PhD, Professor, Amsterdam UMC, Department of Psychiatry, University of Amsterdam, the Netherlands; Anne LingfordHughes, FRCPsych, Consultant Psychiatrist, CNWL Foundation Trust, London and Professor of Addiction Biology, Imperial College London and Head of the Centre for Professor of Addiction Biology, Imperial College London and Head of the Centre for
Psychiatry, Imperial College London, UK; Geraldine Strathdee, FRCPsych, Consultant Psychiatrist, NHS Improvement, UK; Derek K. Tracy, FRCPsych (D), Consultant Psychiatrist, Clinical Director, Oxleas NHS Foundation Trust London and Senior Lecturer, King's College London, UK

Correspondence: MS Josefien Breedvelt, the Mental Health Foundation, Colechurch House 1 London Bridge Walk, London SE1 2SX, UK.

Email: jbreedvelt@mentalhealth.org.uk

First received 6 Jul 2018, final revision 20 Aug 2018, accepted 10 oct 2018

\section{References}

1 Carter A, Croft A, Lukas D, Sandstrom G. Women's Visibility in Academic Seminars: Women Ask Fewer Questions than Men [Blog on the Internet]. LSE, 2018 (http://blogs.Ise.ac.uk/impactofsocialsciences/2018/01/17/women-askfewer-questions-than-men-in-academic-seminars/). 
2 Hewlett SA, Buck Luce C, Servon L, Sherbin L, Shiller P, Sosnovich E, et al. The Athena Factor: Reversing the Brain Drain in Science, Engineering, and Technology. Harvard Business Review, 2008 (http://rachelappel.com/media/ downloads/w_athena_factor.pdf).

3 Medical Schools Council. Survey of Medical Clinical Academic Staffing Levels 2017 [Internet]. Medical Schools Council, 2017 (https://www.medschools.ac.uk/media/2026/medical-clinical-academic-staffing-levels-2017. pdf).

4 Ournals HIGHRJ, Shen YA, Webster JM, Shoda Y, Fine I. Persistent underrepresentation of women's science in high-profile journals. BioRxiv. 2018. DOI: https://doi.org/10.1101/275362

5 Royal College of Psychiatrists. Census 2017: Workforce Figures for Consultant and Specialty Doctor Psychiatrists. Royal College of Psychiatrists, 2017 (https://www.rcpsych.ac.uk/pdf/RCPsych_workforce_census_report 2017. pdf).
6 Boring A, Ottoboni K, Stark PB. Student Evaluations of Teaching are not Only Unreliable, They are Significantly Biased Against Female Instructors. LSE, 2016 (http://blogs.Ise.ac.uk/impactofsocialsciences/2016/02/04/studentevaluationsof-teaching-gender-bias/).

7 Grove J. Female professors 'pay price for academic citizenship.' Times Higher Education World University Ranks, 2016 (https://www.timeshighereducation. com/news/female-professors-pay-price-academic-citizenship).

8 Ovseiko PV, Chapple A, Edmunds LD, Ziebland S. Advancing gender equality through the Athena SWAN Charter for Women in Science: an exploratory study of women's and men's perceptions. BMC 2017; 15(12): 1-13.

9 Goldin C. A grand gender convergence: it's last chapter. AER 2014; 104(4): 1091-119.

10 Clerkin C. What Women Want - And Why you Want Women - In the Workplace. Center for Creative Leadership, 2017 (https://www.ccl.org/wp-content/ uploads/2017/07/WhatWomenWant.FINAL_.pdf).

\section{psychiatry in literature}

\section{The Varieties of Religious Experiences by William James: a 19th-century description of the psychosis spectrum by way of religious and mystical experiences}

\section{Jianan Bao}

Religious and mystical experiences have profound meanings for the lives of people across all cultures. William James, a lecturer in anatomy and physiology at Harvard in the late 19th century, approaches these experiences with an empirical eye, at a time when psychology was beginning to diverge from philosophy. He takes great interest in dissecting the subjective experiences of individuals, drawing upon autobiographies and other first-person accounts of encounters with the divine and in doing so wrote a seminal text about the psychology and psychiatry of religious experiences.

In his book The Varieties of Religious Experiences are found many passages of first-person accounts that contain elements of hallucinations, passivity phenomena, delusional moods and possibly aberrant salience. James acknowledges that he draws upon 'the mass of collateral phenomena, morbid or healthy' to better understand religious phenomena. He maps out these experiences from which he strictly excludes shared experiences through communities, institutions or religious dogma, including only the solitary experiences of individuals. His accounts vary from the mundane to the extreme, distilling from them the characteristics of religious and mystical experiences: ineffability, noetic quality, transiency and passivity.

There are numerous first-person accounts, including the following illustrative excerpts. On the common end of the spectrum: 'When I walk the fields, I am oppressed now and then with a feeling that everything I see has a meaning, if I could but understand it. And this feeling of being surrounded with truths which I cannot grasp amounts to indescribable awe sometimes ...' On the more extreme end: ' ... whilst resting in the afternoon, I suddenly heard as it were these words: "You will be healed and do a work you never dreamed of." These words were impressed upon my mind with such power I said at once that only God could have put them there.' And the more disturbing: 'the word of the Lord came to me again, saying: Cry, "Wo to the bloody city of Lichfield!" So I went up and down the streets, crying with a loud voice, Wo to the bloody city of Lichfield!'

James' medical peers labelled some of these religious persona as epileptics, hysterics and 'hereditary degenerates'. James, however, ardently opposes the view that religious experiences are pathological. He writes, 'The overcoming of all the usual barriers between the individual and the Absolute is the great mystic achievement.' Individuals who have these experiences are religious geniuses, and these experiences are universal. He nevertheless acknowledges that there is a 'diabolical mysticism, a sort of religious mysticism turned upside down ... The same sense of ineffable importance ... voices and visions ... the same controlling by extraneous powers; only this time the emotion is pessimistic'.

James is in fact on a secondary mission to examine the common mechanisms between the pathological and religious experiences, to understand the merits of the latter. In doing so, he could be describing an early prototype of the psychosis spectrum. This perspective is shared across different cultures: for example, there is the Hindu Vedantists' belief in a mystical consciousness where 'There is no feeling of $\mathrm{I}$, and yet the mind works, desireless, free from restlessness ...' , one which some people may stumble into in a way which is impure. To ascertain its purity, the Vedantists looked to the results: whether this experience has changed the individual's life for the better. Across continents and cultures the same argument is echoed by Saint Teresa in her rebuttal against critics: her visions are not pathological, because they have enriched her life and bestowed her with her virtues. There seems to be a way to differentiate between beneficial and maleficent religious experiences; James would argue that this is by looking at their outcomes.

James' investigation of religious and mystical experiences, which explore psychotic experiences as collateral, can inspire the modern psychiatrist not only in its impressive synthesis of varied and rich experiences - a much needed undertaking at a time when the concept of schizophrenia is being deconstructed - but also in its philosophical stance of pragmatism: rather than focusing on the origin of the experience of belief, whether that be through reductive diagnostic criteria, genetics or neurophysiology, focusing instead on the 'way in which it works on the whole' - the impact that the experiences have on the individual. I would like to think that if James were alive today, he would be reaching across disciplines, deconstructing the concept of schizophrenia by way of phenomenology and epidemiology.

Copyright (c) The Royal College of Psychiatrists 2018 